ARTICLE

DOI: $10.1038 / \mathrm{s} 41467-017-01035-2$

\title{
Understanding activity and selectivity of metal-nitrogen-doped carbon catalysts for electrochemical reduction of $\mathrm{CO}_{2}$
}

Wen Ju', Alexander Bagger ${ }^{2}$, Guang-Ping Hao (D) ${ }^{3}$, Ana Sofia Varela ${ }^{1,4}$, llya Sinev ${ }^{5}$, Volodymyr Bon (D) ${ }^{3}$, Beatriz Roldan Cuenya ${ }^{5,6}$, Stefan Kaskel $^{3}$, Jan Rossmeis ${ }^{2} \&$ Peter Strasser $^{1}$

Direct electrochemical reduction of $\mathrm{CO}_{2}$ to fuels and chemicals using renewable electricity has attracted significant attention partly due to the fundamental challenges related to reactivity and selectivity, and partly due to its importance for industrial $\mathrm{CO}_{2}$-consuming gas diffusion cathodes. Here, we present advances in the understanding of trends in the $\mathrm{CO}_{2}$ to $\mathrm{CO}$ electrocatalysis of metal- and nitrogen-doped porous carbons containing catalytically active $\mathrm{M}-\mathrm{N}_{x}$ moieties $(\mathrm{M}=\mathrm{Mn}, \mathrm{Fe}, \mathrm{Co}, \mathrm{Ni}, \mathrm{Cu})$. We investigate their intrinsic catalytic reactivity, $\mathrm{CO}$ turnover frequencies, $\mathrm{CO}$ faradaic efficiencies and demonstrate that $\mathrm{Fe}-\mathrm{N}-\mathrm{C}$ and especially $\mathrm{Ni}-\mathrm{N}-\mathrm{C}$ catalysts rival $\mathrm{Au}$ - and $\mathrm{Ag}$-based catalysts. We model the catalytically active $M-N_{x}$ moieties using density functional theory and correlate the theoretical binding energies with the experiments to give reactivity-selectivity descriptors. This gives an atomicscale mechanistic understanding of potential-dependent $\mathrm{CO}$ and hydrocarbon selectivity from the $M-N_{x}$ moieties and it provides predictive guidelines for the rational design of selective carbon-based $\mathrm{CO}_{2}$ reduction catalysts.

\footnotetext{
${ }^{1}$ Department of Chemistry, Chemical Engineering Division, Technical University Berlin, Berlin 10623, Germany. ${ }^{2}$ Department of Chemistry, University of Copenhagen, Universitetsparken 5, Copenhagen 2100, Denmark. ${ }^{3}$ Department of Inorganic Chemistry, Technical University Dresden, Dresden 01062 , Germany. ${ }^{4}$ Institute of Chemistry, National Autonomous University of Mexico, Mexico City 04510, Mexico. ${ }^{5}$ Department of Physics, Ruhr University Bochum, Bochum 44801, Germany. ${ }^{6}$ Interface Science Department, Fritz-Haber-Institut der Max-Planck Gesellschaft, 14195 Berlin, Germany. Wen Ju and Alexander Bagger contributed equally to this work. Correspondence and requests for materials should be addressed to

G.-P.H. (email: guangping.hao@manchester.ac.uk) or to J.R. (email: jan.rossmeisl@chem.ku.dk) or to P.S. (email: pstrasser@tu-berlin.de)
} 


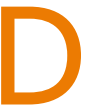

irect electrochemical reduction of $\mathrm{CO}_{2}\left(\mathrm{CO}_{2} \mathrm{RR}\right)$ is a promising early-stage technology to produce commodity chemicals and synthetic fuels. Electricity from renewable sources can provide the input power needed to react water and waste $\mathrm{CO}_{2}$ to produce carbon-based chemicals or fuels in a sustainable manner ${ }^{1}$. The ultimate technological viability of this process, however, is contingent upon the identification of affordable catalyst materials that overcome the challenges regarding the poor product selectivity and poor voltage and energy efficiency ${ }^{2}$.

Metals have been the most common choice as electrocatalysts for the $\mathrm{CO}_{2} \mathrm{RR}$. In early studies, copper was found to be the unique metal able to reduce $\mathrm{CO}_{2}$ into relevant amounts of hydrocarbons ${ }^{3}$. This is why catalysis studies-whenever hydrocarbon products were of primary interest-have invariably focused on $\mathrm{Cu}$ or $\mathrm{Cu}$-derived materials. From these we now know that the reaction conditions such as electrolyte ${ }^{4-6}$ and applied potential ${ }^{3,7}$ can have a significant effect on activity and selectivity of $\mathrm{Cu}$ during the catalytic reaction process. In addition, more recent work evidenced that the morphology of the copper electrode $e^{8}$, its oxidation state $e^{9,10}$, the geometric shape $e^{11-14}$ and size $^{15}$ of the $\mathrm{Cu}$ nanoparticles, the interparticle distance ${ }^{16,17}$, as well as the presence of a second metal ${ }^{18-20}$ also play a crucial role for the resulting catalytic performance.

In contrast to hydrocarbon formation, the $\mathrm{CO}_{2}$ reduction to $\mathrm{CO}$ requires only two electron/proton transfers, which makes it a substantially less hindered process. The formation of $\mathrm{CO}$ is usually accompanied by HER resulting in syngas production, which can be used as feedstock in synthetic fuels production via the catalytic Fischer-Tropsch process. The chloralkaline electrolysis-based polyurethane and polycarbonate industries, however, strive to adopt an electrocatalytic cathodic reduction of $\mathrm{CO}_{2}$ to pure $\mathrm{CO}$ streams for production of phosgene intermediate further downstream. Such innovative $\mathrm{CO}_{2}$-depletion cathodes coupled to the anodic chlorine production electrode are still in early-stage research and currently require first and foremost fundamental advances in our understanding of the catalytic mechanism and the identification of suitable efficient catalysts.

It has been shown that $\mathrm{Ag}^{21,22}, \mathrm{Au}$-derived ${ }^{23-28}$ and bimetallic $\mathrm{Cu}-\mathrm{In}^{19}$ and $\mathrm{Cu}-\mathrm{Sn}^{20}$ catalysts can selectively reduce $\mathrm{CO}_{2}$ to $\mathrm{CO}$ at low overpotentials. However, despite their promising performance, alternative earth-abundant catalyst materials are desired. Molecular catalysts based on Iron-Porphyrin showed some $\mathrm{CO}_{2}$ to $\mathrm{CO}$ reactivity in DMF solution ${ }^{29-31}$, and so did metal-organic frameworks ${ }^{32}$ and immobilized porphyrins ${ }^{33-35}$. Unfortunately, these material concepts severely suffer from low electric conductivity and hence are not suitable as $\mathrm{CO}_{2}$ reduction catalysts at large current densities.

A promising recent alternative to expensive noble metals are solid doped carbon-based powder catalysts, similar to those developed for oxygen reduction reaction in recent years ${ }^{36-40}$. In recent studies, metal-free, nitrogen-doped carbon catalysts $(\mathrm{N}-\mathrm{C})$ have been proven capable to efficiently reduce $\mathrm{CO}_{2}$ to single- and multi-carbon species and both experimental and computational studies have pointed toward pyridinic- $\mathrm{N}$ as the active site ${ }^{41-46}$. More recent studies evidenced that the metal centers are in fact crucial for the $\mathrm{CO}_{2} \mathrm{RR}$ to $\mathrm{CO}$. Varela et al. ${ }^{33}$ have tested the PANI-derived catalysts as $\mathrm{CO}_{2} \mathrm{RR}$ catalyst and shown that the addition of metal resulted in a strongly enhanced $\mathrm{CO}_{2} \mathrm{RR}$ activity and the generation of $\mathrm{CO}$. More interestingly, trace amounts of $\mathrm{CH}_{4}$ were detected ${ }^{33}$. Consistently, DFT studies on transition metal based porphyrin-like catalysts suggested that depending on the metal center, ${ }^{*} \mathrm{CO}$ can be further reduced ${ }^{47}, 48$. A detailed fundamental mechanistic understanding of the $\mathrm{CO}_{2}$ reduction reactivity and selectivity of single-site metal-nitrogen-doped carbons is still missing. This contribution will change that.

Here, we explore an entire family of single site, N-coordinated transition metal-doped nanoporous carbon materials (henceforth
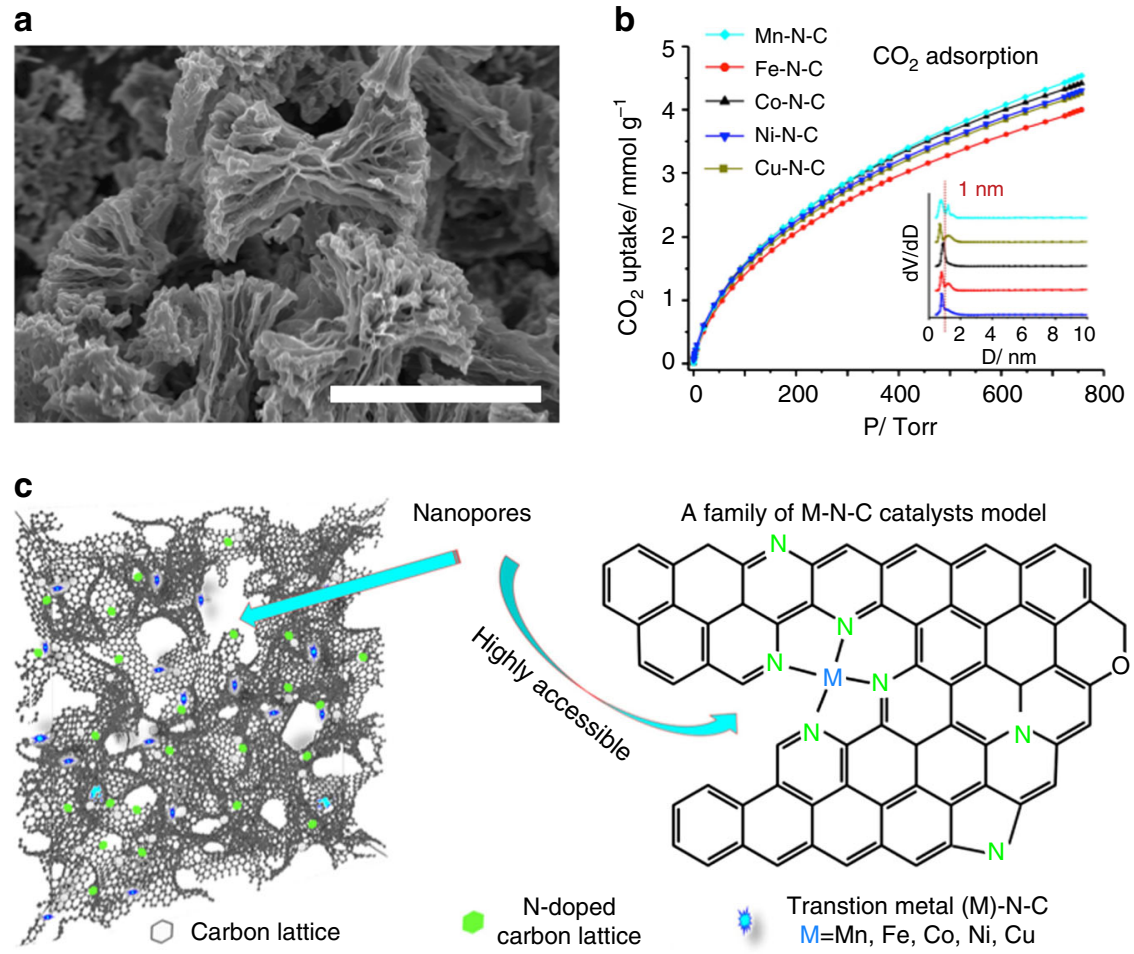

Fig. 1 Visualization, porosity and illustration of the $\mathrm{M}-\mathrm{N}-\mathrm{C}$ catalyst. a Typical SEM image of the family of N-coordinated metal-doped (M-N-C) carbon electro-catalysts, scale bar $=4 \mu \mathrm{m} ; \mathbf{b} \mathrm{CO}_{2}$ physisorption isotherm $(273 \mathrm{~K})$; inset: the pore size distribution; c Materials model and a schematic local structure 

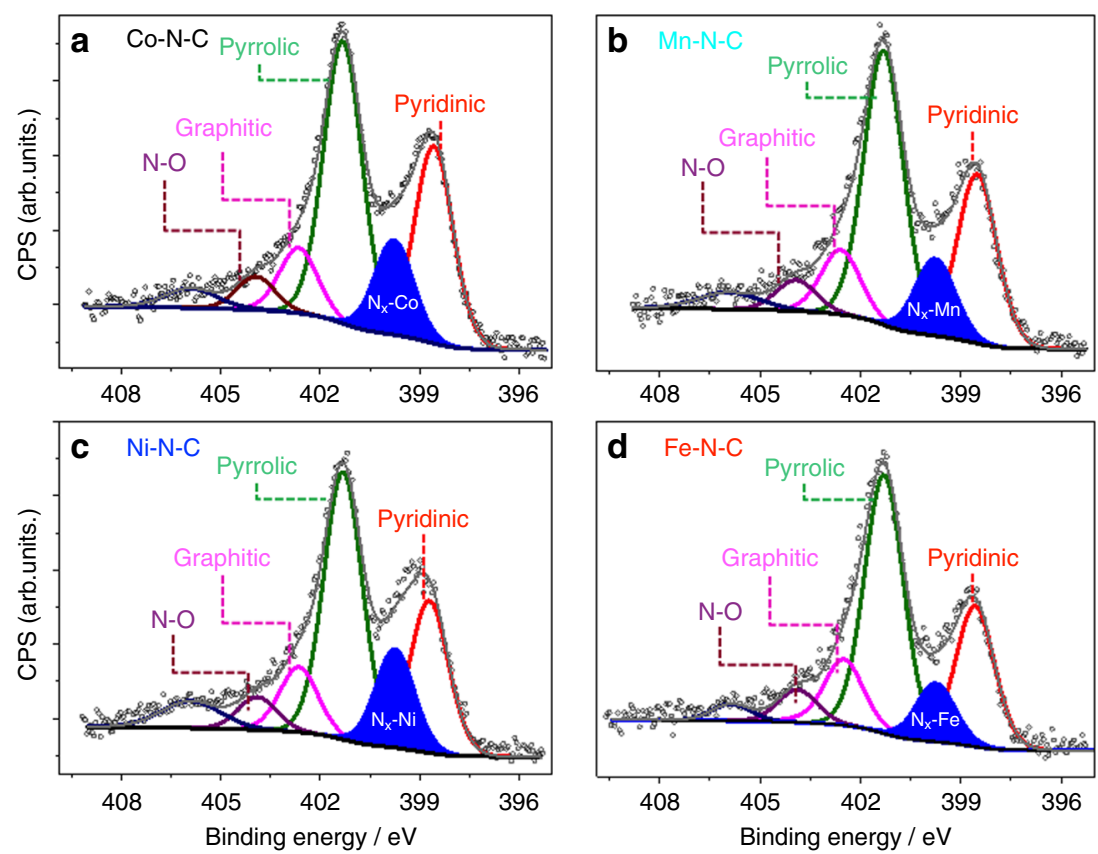

Fig. 2 High-resolution XPS characterization. N-1s XPS core level region of a Co, $\mathbf{b} \mathrm{Mn}, \mathbf{c} \mathrm{Ni}$ and $\mathbf{d}$ Fe doped $\mathrm{M}-\mathrm{N}-\mathrm{C}$ catalyst. The $2 \mathrm{p}_{3 / 2}$ spectra of the corresponding metal peaks (Co-2p, Mn-2p, Ni-2p, Fe-2p) is shown in Supplementary Fig. 9

referred to as $\mathrm{M}-\mathrm{N}-\mathrm{C}$ catalysts) as single-site electro-catalysts for the $\mathrm{CO}_{2} \mathrm{RR}$. Using a combined experimental and computational approach we investigate the catalyst activity and product efficiency (catalyst selectivity) and unravel their mechanistic origins in terms of binding energies and energetic reaction paths. This family of $\mathrm{M}-\mathrm{N}-\mathrm{C}$ materials comprises highly accessible and homogeneously dispersed $\mathrm{M}-\mathrm{N}_{x}$ sites, displays balanced surface wettability and low valence metal species, which exhibit impressively high activity and remarkable selectivity at low overpotential for the $\mathrm{CO}_{2} \mathrm{RR}$ to $\mathrm{CO}$ and hydrocarbons. We show that these catalysts are comparable alternatives to Au-based catalysts in future industrial $\mathrm{CO}_{2}$-consumption gas diffusion cathodes (CCCs). Density functional theory (DFT) calculations offer firstof-its-kind mechanistic insight into the rate- and selectivity determining processes on the single-site metal-nitrogen centers. We show that the binding energies of intermediates to the $\mathrm{M}-\mathrm{N}_{x}$ moieties provide excellent descriptors to predict, and understand the mechanistic details of the $\mathrm{CO}_{2} \mathrm{RR}$ activity and selectivity of this family of catalysts over a wide overpotential range.

\section{Results}

Synthesis and characterization. We have synthesized a family of $\mathrm{M}-\mathrm{N}-\mathrm{C}$ electrocatalysts starting with bipyridine-based coordinated polymers and a variety of transition metals such as $\mathrm{Mn}, \mathrm{Fe}, \mathrm{Co}, \mathrm{Ni}$, and $\mathrm{Cu}$. Materials characterization started with morphological and gas adsorption experiments (Fig. 1a, b). The $\mathrm{M}-\mathrm{N}-\mathrm{C}$ electrocatalysts showed hierarchical chemical structures with visible macropores (Fig. 1a, Supplementary Fig. 1). The pore size distribution peaks narrowly at ca. $0.7-0.8 \mathrm{~nm}$ (2.5-2.9 times of the dynamic diameter of $\mathrm{CO}_{2}$ molecules, Fig. $1 \mathrm{~b}$ inset), enabling this family $\mathrm{M}-\mathrm{N}-\mathrm{C}$ materials a remarkable 4.0-4.5 $\mathrm{mmol} \mathrm{g}^{-1}$ capacity for $\mathrm{CO}_{2}$ capture at atmospheric pressure (Fig. 1b) due to their high-adsorption potential to trap $\mathrm{CO}_{2}$ molecules ${ }^{49}$. This could result in $\mathrm{CO}_{2}$ enrichment within a local environment despite the low $\mathrm{CO}_{2}$ solubility in the working electrolyte. Figure 1c displays a structural illustration of the interconnected macropore walls, composed of thin carbon branches with highly accessible micropores, all over which the coordinated metal sites as well as $\mathrm{N}$-containing carbon lattice are homogeneously distributed.

The $\mathrm{N}_{2}$ physisorption isotherms (Supplementary Fig. 2) are essentially type I for $\mathrm{Cu}, \mathrm{Co}, \mathrm{Ni}$, or $\mathrm{Mn}-\mathrm{N}-\mathrm{C}$ samples, indicating their microporous nature, while the visible hysteresis of $\mathrm{Fe}-\mathrm{N}-\mathrm{C}$ material reveals the presence of a small fraction of mesopores in addition to micropores. Notably, a significant increase of gas uptake was observed at higher relative pressure $\left(P / P_{0}>0.9\right)$ for all $\mathrm{M}-\mathrm{N}-\mathrm{C}$ samples, indicating their rich macroporosity, which is consistent with the SEM images (Fig. 1a). The specific surface area based on Brunauer-Emmett-Teller (BET) theory is in range of $615-938 \mathrm{~m}^{2} \mathrm{~g}^{-1}$, while the $\mathrm{Ni}-\mathrm{N}-\mathrm{C}$ and $\mathrm{Mn}-\mathrm{N}-\mathrm{C}$ show the lowest and the highest BET surface area, respectively, and the others are in between (Supplementary Table 1). This shows a roughly linear relationship with the double layer capacity under the electrochemical condition (Supplementary Fig. 3, Supplementary Table 1). The M-N-C samples showed a moderate hydrophilic character (Supplementary Fig. 4) and comparable defect site density (Supplementary Fig. 5, Supplementary Table 2). The XRD patterns (Supplementary Fig. 6) reflect the predominant amorphous carbon support, particularly for $\mathrm{Mn}, \mathrm{Co}, \mathrm{Ni}$ or $\mathrm{Cu}-\mathrm{N}-\mathrm{C}$; while the presence of $\mathrm{Fe}$, to some extent, led to graphitic domains. Some residual $\mathrm{Fe}, \mathrm{Co}, \mathrm{Ni}$ in a metallic state was detectable after the $\mathrm{H}_{2}$ reduction at $900^{\circ} \mathrm{C}$. The STEM elemental mappings (Supplementary Fig. 7) are fully consistent with the XRD findings showing presumably carbon-encapsulated metal particles as well as coordinated metal ion sites for the three catalysts.

Catalyst surface. The catalyst surface chemical composition and state were investigated using X-ray photoelectron spectroscopy (XPS). Fitted high-resolution N 1 s spectra (Fig. 2 for Co, Mn, Ni, $\mathrm{Fe}$, and Supplementary Fig. 8 for $\mathrm{Cu}$, detailed fitted parameters in Supplementary Table 3) evidenced the presence of the porphyrinlike metal-coordinated $\mathrm{M}-\mathrm{N}_{\mathrm{x}}$ moieties $(399.7 \mathrm{eV})$, as well as pyrrolic $(401.3 \mathrm{eV})$, pyridinic $(398.6 \mathrm{eV})$, graphitic $(402.5 \mathrm{eV})$, and $\mathrm{N}-\mathrm{O}_{x}(403.9 \mathrm{eV})$ species (Fig. 2$)^{50,51}$. In addition, a weak and broad peak can be fitted at higher binding energies, centered at $405.9 \mathrm{eV}$, which is likely assigned to trace amounts of 

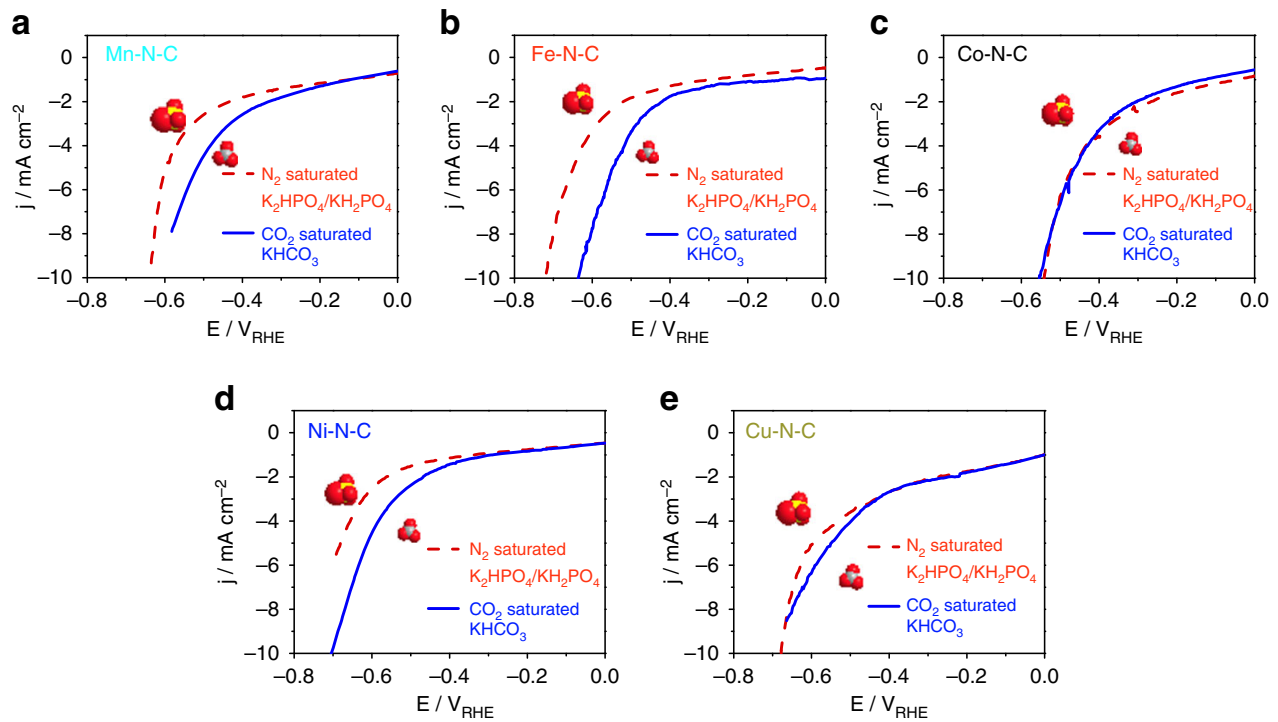

Fig. $3 \mathrm{CO}_{2}$ reduction reaction activities. Linear sweep voltammetry of a Mn-N-C, b Fe-N-C, c Co-N-C, d Ni-N-C and e Cu-N-C in CO - saturated $0.1 \mathrm{M}$ $\mathrm{KHCO}_{3}$ (solid lines) and in $\mathrm{N}_{2}$-saturated $0.1 \mathrm{M} \mathrm{KH}_{2} \mathrm{PO}_{4} / \mathrm{K}_{2} \mathrm{HPO}_{4}$ (dashed lines) with a catalyst loading of $0.76 \mathrm{mg} \mathrm{cm}^{-2}$ at $5 \mathrm{mV} \mathrm{s}^{-1}$ in cathodic direction
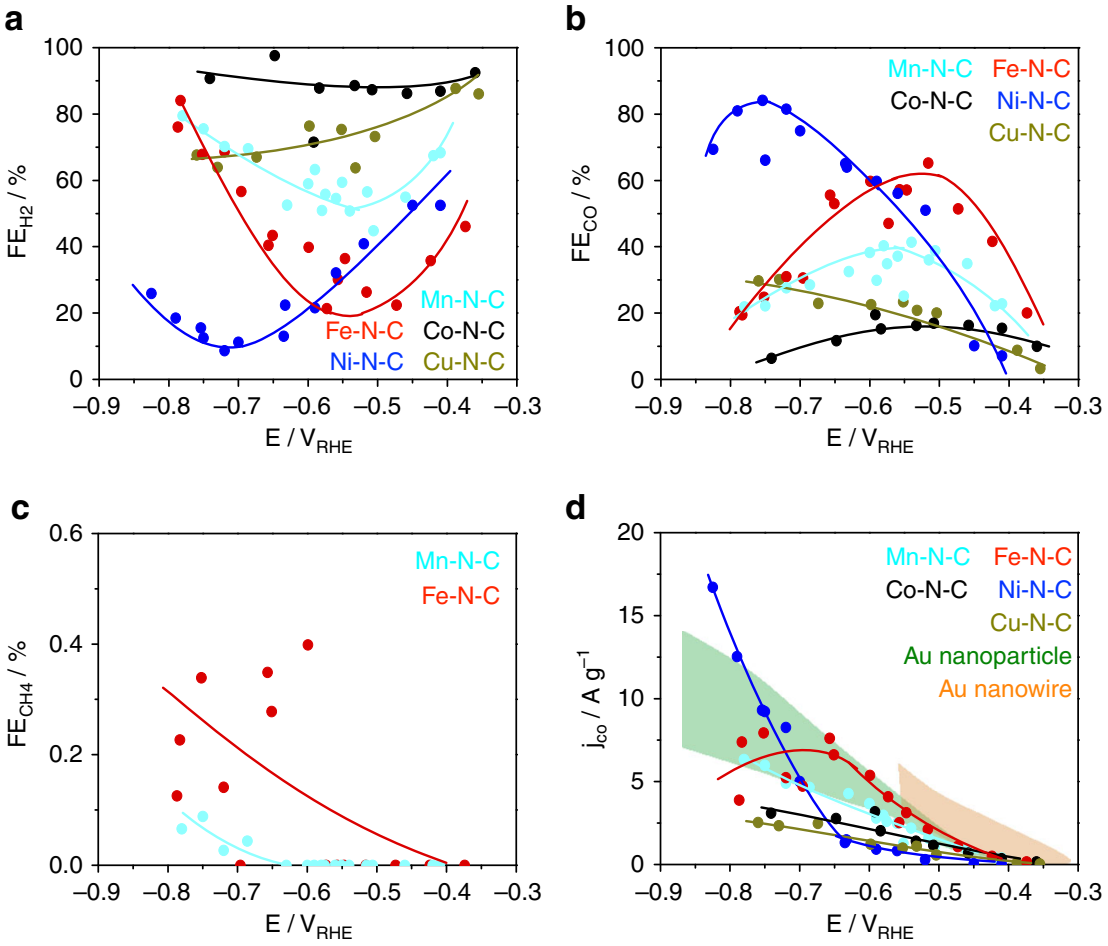

Fig. 4 Catalytic performance and product analysis. a-c Faradaic Efficiencies (FE) vs. applied, IR-corrected electrode potential of a $\mathrm{H}_{2}$, $\mathbf{b} \mathrm{CO}_{\text {and }} \mathbf{c} \mathrm{CH}_{4}$. d Catalyst mass-normalized CO partial currents (mass activity) vs. applied potential for the five $\mathrm{M}-\mathrm{N}-\mathrm{C}$ catalysts compared to state-of-art Au catalysts (performance ranges of Au-nanoparticle and Au-nanowires are shown by filled areas $25-27$. Lines to guide the eye. Conditions: 60 min at constant electrode potential in $\mathrm{CO}_{2}$-saturated $0.1 \mathrm{M} \mathrm{KHCO}_{3}$ with $0.76 \mathrm{mg} \mathrm{cm}^{-2} \mathrm{M}-\mathrm{N}-\mathrm{C}$ catalysts loading. Faradaic efficiencies and $\mathrm{CO}$ yields after 15 min are shown in Supplementary Fig. 11

non-decomposed nitrogen precursors ${ }^{52}$. The N $1 \mathrm{~s}$ spectra of all samples are dominated by pyrrolic nitrogen (Supplementary Table 3), whereas the $M-N_{x}$ moiety gives rise to the most intense core level for the $\mathrm{Ni}$-doped sample. A detailed analysis of the metal $2 p_{3 / 2}$ shake-up photoemission lines (insets of Fig. 2) offering insight in the chemical state of the metallic species is presented in Supplementary Fig. 9. Combined, our materials characterization confirmed the prevalent presence of
$\mathrm{N}$-coordinated metal single-site moieties, $\mathrm{M}-\mathrm{N}_{x}$, near the surface in all catalyst samples, except for the $\mathrm{Cu}$ sample that exhibited evidence of near-surface metallic $\mathrm{Cu}$ particles (Supplementary Fig. 8).

Catalytic sensitivity towards $\mathrm{CO}_{2}$. As a first test of the total faradaic reactivity of our single-site solid catalysts in $\mathrm{CO}_{2}$-saturated $0.1 \mathrm{M} \mathrm{KHCO}_{3}$, comprising both the $\mathrm{HER}$ and $\mathrm{CO} 2 \mathrm{RR}$, 


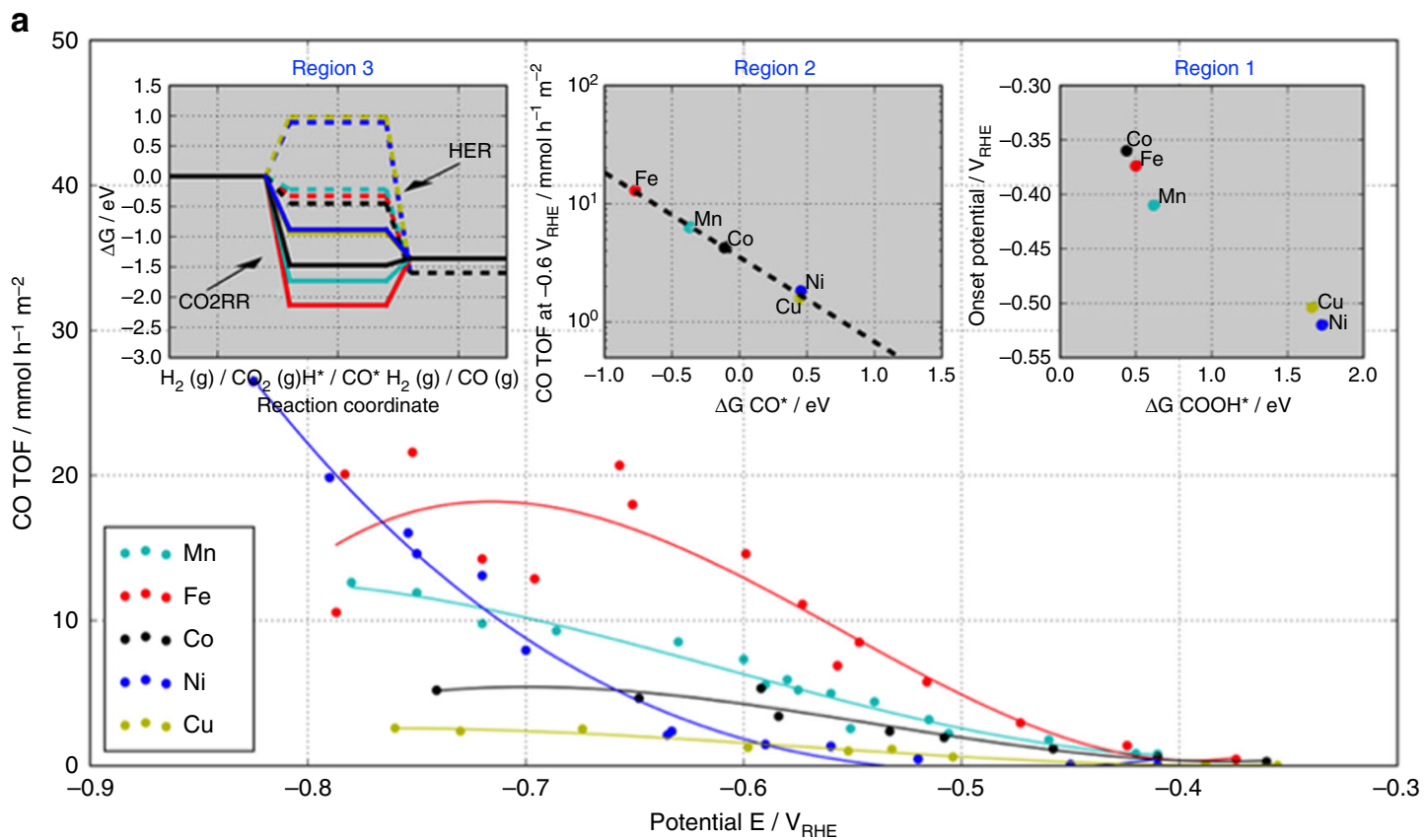

b
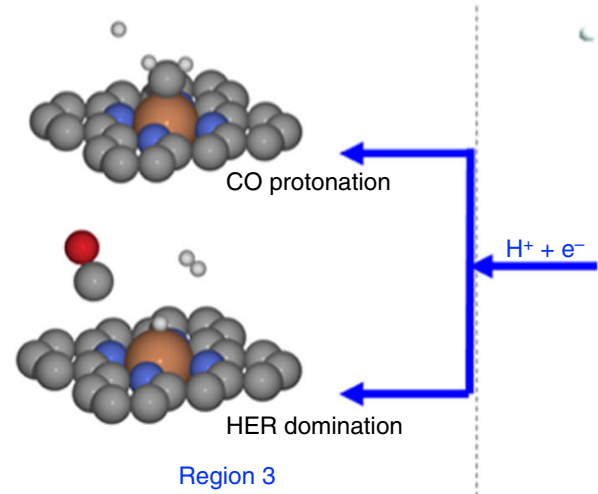

$\leftarrow \mathrm{H} \odot \mathrm{C}$

- N O O

Metal $=\mathrm{Mn}, \mathrm{Fe}, \mathrm{Co}, \mathrm{Ni}, \mathrm{Cu}$

Region 3

Region 2

Region 1

Fig. 5 Experimental correlation to simulations. Experimental CO production turnover frequency (TOF) of the M-N-C catalysts vs. applied IR-corrected electrode potential (see Supplementary Equation 4). The catalytic reactivity trends a and reaction pathway $\mathbf{b}$ split into 3 potential regions with distinctly different rate-determining mechanistic features. Insets: Region 1: Low overpotentials, the experimental onset potentials of CO production (better seen on the $\log$ (CO TOF) -E plot in Supplementary Fig. 15) correlate with the binding energy of the reaction intermediate $\mathrm{COOH}^{\star}$ taken from Supplementary Fig. 14. Region 2: Intermediate over-potentials, $C O$ production TOF at $-0.6 \mathrm{~V}_{\mathrm{RHE}}$ correlates with the free energy of adsorbed $\mathrm{CO}, \mathrm{CO}^{\star}$ taken from Supplementary Fig. 14; Region 3: High overpotentials, free energy diagrams for the HER (dashed paths) and CO2RR (solid paths) at $-0.8 V_{R H E}$ for each $\mathrm{M}-\mathrm{N}-\mathrm{C}$ catalyst. HER barriers are high for $\mathrm{Ni}$ and $\mathrm{Cu}$, while CO2RR is downhill making these materials favorable CO producing catalysts

Linear Sweep Voltammetry (LSV) were performed between 0.0 and $-0.7 \mathrm{~V}$ vs. RHE, blue solid curves in Fig. 3. Comparison with LSVs performed in absence of $\mathrm{CO}_{2}$ (red dashed curves) revealed substantial $\mathrm{CO}_{2} \mathrm{RR}$ activity of the $\mathrm{Mn}, \mathrm{Fe}, \mathrm{Ni}$, and $\mathrm{Cu}$-doped catalysts. Furthermore, the $\mathrm{Mn}, \mathrm{Fe}, \mathrm{Ni}$, and $\mathrm{Cu}$-doped samples exhibited an earlier onset (smaller overpotential) for the $\mathrm{CO}_{2} \mathrm{RR}$ than HER, suggesting that, at least in a small potential window, they are selective towards CO2RR. By contrast, $\mathrm{Co}-\mathrm{N}-\mathrm{C}$ presented a comparable activity suggesting that the HER may be the dominant faradic process over the investigated potential range.

Catalytic performance tests were conducted under potential control during $1 \mathrm{~h}$ electrolysis. The geometric electrode areanormalized $\left(\mathrm{j}_{\text {geo }}\right)$ and the active interfacial area-normalized (double-layer capacity-normalized) faradaic currents $\left(j_{D L}\right)$ after $15 \mathrm{~min}$ and $60 \mathrm{~min}$ are compared in Supplementary Fig. 10. The $\mathrm{Co}-\mathrm{N}-\mathrm{C}$ catalyst generated the most overall faradaic current, while the $\mathrm{Cu}-\mathrm{N}-\mathrm{C}$ displayed the poorest overall reactivity at larger overpotentials, in accordance with Fig. 3.
Faradaic efficiencies and absolute yields. The stationary faradaic efficiencies (FE) of the three principal $\mathrm{CO}_{2} \mathrm{RR}$ products after 60 min electrolysis are displayed in Fig. 4. $\mathrm{H}_{2}$ and $\mathrm{CO}$ accounts for up to $95 \%$ of the transferred charge on the single-site catalysts (see Supplementary Eqs. 1-3. Product distribution at $15 \mathrm{~min}$ is shown in Supplementary Fig. 11). Remarkably, small amounts of methane were detected, however only on Fe and Mn catalysts, while no liquid product could be detected. Despite the low number of active surface single-sites on the $\mathrm{M}-\mathrm{N}-\mathrm{C}$ catalysts, their mass-based $\mathrm{CO}$ partial currents (production rate) are comparable to that of Au-based catalysts ${ }^{25}, 26$, especially at technologically interesting higher currents (Fig. 4d). These results highlight the significance of this family of compounds as nonprecious, earth-abundant low-cost and efficient $\mathrm{CO}_{2} \mathrm{RR}$ catalyst alternatives for the electrochemical production of $\mathrm{CO}$ in $\mathrm{CO}_{2-}$ consuming electrodes.

To arrive at a fundamental mechanistic understanding of the $\mathrm{CO}_{2}$ catalysis on the single-site materials, we focus on reactivity 
trends among the $\mathrm{M}-\mathrm{N}-\mathrm{C}$ catalysts at different applied overpotentials. The $\mathrm{CO}_{2} \mathrm{RR}$ performance tests exhibit a strong dependence on the nature of the transition metal, not only in terms of the molar $\mathrm{CO} / \mathrm{H}_{2}$ ratio, but also in the experimental overpotential at maximum $\mathrm{CO}$ efficiency (see Fig. $4 \mathrm{a}$ and b). $\mathrm{H}_{2}$ $\mathrm{FE}$ on $\mathrm{Co}-\mathrm{N}-\mathrm{C}$ remains above $80 \%$ over the entire electrode potential range, making it a catalyst with poor selectivity towards $\mathrm{CO}_{2} \mathrm{RR}$. On the other hand, $\mathrm{Fe}-\mathrm{N}-\mathrm{C}$ and particularly $\mathrm{Ni}-\mathrm{N}-\mathrm{C}$ catalysts clearly act as highly promising catalyst for selective $\mathrm{CO}$ production, however, the maximum $\mathrm{CO} F E$ is obtained at a smaller overpotential on Fe-N-C $\left(\mathrm{V}_{\mathrm{RHE}}=-0.55 \mathrm{~V}, \mathrm{FE}_{\mathrm{CO}}=65 \%\right)$ than on $\mathrm{Ni}-\mathrm{N}-\mathrm{C}\left(\mathrm{V}_{\mathrm{RHE}}=-0.78 \mathrm{~V}, \mathrm{FE}_{\mathrm{CO}}=85 \%\right)$. Note that the selectivity of these two single site catalysts is drastically different from that of metallic $\mathrm{Ni}$ and $\mathrm{Fe}$ catalysts, which yield $\mathrm{H}_{2}$ as virtually the only major product ${ }^{23}$. We have conducted a number of control measurements to confirm that the $\mathrm{M}-\mathrm{N}_{x}$ site is indeed the most significant active center for $\mathrm{CO}_{2}$ reduction into $\mathrm{CO}$. First, the Nitrogen Free $\mathrm{M}-\mathrm{C}$ as well as the polymer precursor before pyrolysis ( $\mathrm{Cu}$-Bpy) contributes negligibly to the $\mathrm{CO}$ activity during the $\mathrm{CO}_{2} \mathrm{RR}$ process. Second, we could not exclude some catalytic activity of the Nitrogen functionalities. However, based on their finite $\mathrm{CO}_{2} \mathrm{RR}$ catalytic reactivity and the rough similarity of the distribution in the $\mathrm{M}-\mathrm{N}-\mathrm{C}$ catalysts, their effect could be seen as a known weak background signal for all cases (Supplementary Table 3, Supplementary Fig. 12 and 13). This finding strongly suggests that the $\mathrm{CO}_{2} \mathrm{RR}$ (to $\mathrm{CO}$ ) reactivity trends purely originate from the differences in intrinsic catalytic activity of the various $\mathrm{M}-\mathrm{N}_{x}$ moieties.

Atomistic insight into the $\mathrm{M}-\mathrm{N}-\mathrm{C}$ activities. To bring theoretical mechanistic insight, DFT simulations pertaining to the $\mathrm{CO}_{2}$ reduction process on $\mathrm{N}$-coordinated metal-doped $\mathrm{M}-\mathrm{N}-\mathrm{C}$ catalysts were carried out. For this purpose we took the single-site motif $\mathrm{M}-\mathrm{N}_{4}$ as active site to calculate the binding energy of the different reaction intermediates (Supplementary Fig. 14). We note that there exist other $\mathrm{M}-\mathrm{N}_{x}$ functionalities ${ }^{53-55}$; however, previously we computationally found the metal to be the dominating factor as compared to other $\mathrm{M}-\mathrm{N}_{x}$ functionalities ${ }^{56}$. Thus, the $\mathrm{M}-\mathrm{N}_{4}$ site appears to be a reasonable single active site model for our analysis here. For the model we calculate the binding energies without electrolyte, which is reasonable for the trends and conclusions drawn here. While activity can often be associated with a single descriptor, selectivity can obviously not, as it is related to competition between different possible reaction paths. The different reaction paths show different dependence on metal center and potential.

Figure 5 compares the trends in the experimental CO-specific turnover frequencies (TOF) of the five $\mathrm{M}-\mathrm{N}-\mathrm{C}$ catalysts. The TOF values were derived from the absolute $\mathrm{CO}$ production rates normalized by the respective BET surface area-weighted surface $\mathrm{M}-\mathrm{N}_{x}$ concentration (Supplementary Equation 4). Correlating the experimental TOF trends and predicted DFT theoretical energy diagrams we were able to identify three regions of distinct reaction dynamics that control the electrocatalysis: First, Region 1, a dynamic regime at low overpotentials near the onset of the CO production, Then, Region 2, a dynamic regime at intermediate overpotentials and finally, Region 3, at larger overpotentials where the $\mathrm{CO}_{2}$ reduction current densities approach technologically relevant levels. The reason for this division is that the order in catalytic activity change in the different regions indicating that the rate in the different regions is determined by a distinctly different surface chemistry.

Low overpotential regime around $-0.45 V_{\text {RHE }}$ (Region 1). Defining the CO production onset potential to be the applied electrode potential at which the $\mathrm{CO}$ TOF exceeds $0.2 \mathrm{mmol} /(\mathrm{h}$ $\mathrm{m}^{2}$ active), the $\mathrm{Fe}, \mathrm{Mn}$ and $\mathrm{Co}-\mathrm{N}-\mathrm{C}$ catalysts start producing $\mathrm{CO}$ at around $-0.4 \mathrm{~V}$ vs. $\mathrm{RHE}$, while the $\mathrm{Cu}$ and $\mathrm{Ni}$ samples require considerable higher overpotentials, see Region 1 inset in Fig. 5. The onset potential is determined by the mechanistic elementary step that is the last to become exergonic as the overpotential is increased (limiting potential). Simulations suggest that this potential-determining step is the first proton-coupled electron transfer reduction of $\mathrm{CO}_{2}$ to adsorbed $\mathrm{COOH}$ according to

$$
\mathrm{CO}_{2}+\mathrm{H}^{+}+\mathrm{e}^{-} \rightarrow \mathrm{COOH}^{*}
$$

In agreement with electrochemical measurements, in the simulations the catalyst falls into two groups: Co, Fe and $\mathrm{Mn}$ requiring only a small overpotential, whereas $\mathrm{Cu}$ and $\mathrm{Ni}$ need a larger thermodynamic driving force for that step.

Intermediate overpotential regime around $-0.6 \mathrm{~V}_{\mathrm{RHE}}$ (Region 2). Here, the $\mathrm{Fe}$ - and $\mathrm{Co}-\mathrm{N}-\mathrm{C}$ catalysts approach their maximum $\mathrm{CO}_{2} \mathrm{RR}$ reactivity, while the $\mathrm{Ni}-\mathrm{N}-\mathrm{C}$ catalyst has barely passed above its $\mathrm{CO}$ production onset. With the electrode potential being now past the limiting electrode potential, the overall $\mathrm{CO}_{2}$ reduction reaction invariably becomes limited by a non-faradaic chemical reaction step. The larger the thermodynamic driving force of this step, the faster the overall reaction rate. Correlating experiments to DFT calculations reveals that the logarithm of the experimental CO TOF is now linearly related to the $\mathrm{CO}^{\star}$ binding energy descriptor, see Region 2 inset in Fig. 5. This suggests that the rate-controlling intermediate has shifted from $\mathrm{COOH}^{\star}$ to $\mathrm{CO}^{*}$. As a result of this, the overall reaction rate appears limited by the process

$$
\mathrm{COOH}^{*}+\mathrm{H}^{+}+\mathrm{e}^{-} \rightarrow \mathrm{CO}^{*}+\mathrm{H}_{2} \mathrm{O}
$$

While DFT predictions do not allow us to unambiguously pinpoint the exact rate-limiting point along the reaction coordinate of step (2), we hypothesize that it is the chemical dissociative formation of $\mathrm{H}_{2} \mathrm{O}$ according to $\mathrm{COOHH}^{*} \rightarrow \mathrm{CO}^{*}+$ $\mathrm{H}_{2} \mathrm{O}$. The stronger $\mathrm{CO}^{*}$ binds, the more driving force is available for this step. An evidence for the hypothesis can be considered by comparing the $\mathrm{Fe}-$ and $\mathrm{Mn}-\mathrm{N}-\mathrm{C}$, which have almost similar $\mathrm{COOH}^{*}$ and $\mathrm{H}^{*}$ binding. However, these descriptors cannot explain the experimental different CO TOF from the two, while the logarithm to the $\mathrm{CO}^{\star}$ descriptor can. (Supplementary Fig. 15)

Large overpotential regime $<-0.7 \mathrm{~V}_{\mathrm{RHE}}$ (Region 3 ). Here, the experimental $\mathrm{CO}$ formation TOF in Fig. 5, as well as the faradaic $\mathrm{CO}$ efficiencies of the $\mathrm{Fe}-\mathrm{N}-\mathrm{C}$ and $\mathrm{Co}-\mathrm{N}-\mathrm{C}$ catalysts have passed their maximum and trend downward (Fig. 4), that of $\mathrm{Mn}-\mathrm{N}-\mathrm{C}$ is levelling off, while the $\mathrm{Ni}-\mathrm{N}-\mathrm{C}$ catalyst continues to increase its $\mathrm{CO}$ production rate at a very high faradaic $\mathrm{CO}$ efficiency, significantly outperforming all other single-site catalysts as well as Au catalysts.

Our mechanistic DFT analysis shown in inset (Region 3) of Fig. 5 is able to consistently explain all these experimental findings. The free energy diagrams of the HER (dashed) and $\mathrm{CO}_{2} \mathrm{RR}$ (solid) evidences that the $\mathrm{Fe}-$, $\mathrm{Co}$ - and Mn-based catalysts start to strongly catalyze the hydrogen evolution reaction $\left(\mathrm{H}^{+}+\mathrm{e}\right.$ $-\rightarrow \mathrm{H}^{*} \rightarrow \mathrm{H}_{2(\mathrm{~g})}$ ) illustrated by the all downhill reaction energy pathways. Among them, $\mathrm{Co}-\mathrm{N}-\mathrm{C}$ is the most efficient HER catalyst and, thus, displays the highest faradaic efficiency for hydrogen evolution, see Fig. 4 . In contrast, the $\mathrm{Ni}$ - and $\mathrm{Cu}$-based catalysts exhibit very weak binding of $\mathrm{H}^{*}$ which makes the HER thermodynamically unfavorable at $-0.8 \mathrm{~V}_{\mathrm{RHE}}$, giving rise to low faradaic hydrogen efficiencies.

The DFT predictions of the $\mathrm{CO}_{2} \mathrm{RR}$ pathway $\left(\mathrm{CO}_{2} \rightarrow \mathrm{CO}^{*} \rightarrow\right.$ $\left.\mathrm{CO}_{(\mathrm{g})}\right)$ at $-0.8 \mathrm{~V}_{\mathrm{RHE}}$ complete the mechanistic picture. While the 
$\mathrm{Ni}-\mathrm{N}_{x}$ and $\mathrm{Cu}-\mathrm{N}_{x}$ moieties stand out as the single sites with the weakest binding to $\mathrm{COOH}^{*}$ and therefore with the largest overpotential to start $\mathrm{CO}_{2}$ reduction (see Region 1), their weak binding of $\mathrm{CO}^{*}$ prevents the potential-independent chemical CO-desorption process $\left(\mathrm{CO}^{*} \rightarrow \mathrm{CO}_{(\mathrm{g})}\right)$ to become rate-limiting. This is in contrast with the $\mathrm{Mn}, \mathrm{Fe}, \mathrm{Co}-\mathrm{N}_{x}$ sites whose $\mathrm{CO}$ TOF is controlled by the $\mathrm{CO}^{*} \rightarrow \mathrm{CO}_{(\mathrm{g})}$ step due to their strong $\mathrm{CO}^{*}$ binding (solid pathways in Region 3) leading to a positive $\Delta \mathrm{G}$ of $\mathrm{CO}$ desorption. Indeed, experimentally, the CO TOF values of the $\mathrm{Mn}, \mathrm{Co}$, and $\mathrm{Fe}-\mathrm{N}-\mathrm{C}$ level off or slow down, while the hydrogen evolution accelerates.

We note that the relatively strong binding of $\mathrm{CO}^{*}$ on $\mathrm{Fe}-\mathrm{N}_{x}$ and $\mathrm{Mn}-\mathrm{N}_{x}$ single sites predicted for Region 3 is fully supported by the experimentally confirmed exclusive ability of these two catalysts to produce the hydrocarbon $\mathrm{CH}_{4}$, see Fig. 4 . In simple terms, one could say that to produce subsequent reaction products from $\mathrm{CO}$ during the $\mathrm{CO}_{2} \mathrm{RR}$, the $\mathrm{CO}$ molecule must be bound strong and long enough to undergo subsequent dissociation and hydrogenation steps to arrive at $\mathrm{CH}_{4}$. For the $\mathrm{Ni}$ and $\mathrm{Cu}$ catalysts, the $\mathrm{CO}^{*}$ detaching is energetically all downhill reaction which prevents further transformations. This makes $\mathrm{Ni}-\mathrm{N}_{x}$ and $\mathrm{Cu}-\mathrm{N}_{x}$ single-site catalysts ideal electrochemical CO producers. We note that the experimentally observed reactivity trend of the $\mathrm{Cu}-\mathrm{N}_{x}$ catalysts in region 3 does not closely follow that of Ni. This is due to a DFT-predicted thermodynamic instability (not shown) of the $\mathrm{Cu}-\mathrm{N}_{x}$ moiety under the strongly reducing conditions of $<-0.7 \mathrm{~V}_{\mathrm{RHE}}$ in region 3. As a result of this, the $\mathrm{N}$-coordinated $\mathrm{Cu}$ ions spontaneously reduce to metallic $\mathrm{Cu}$ nanoparticles-as confirmed by our XPS results-which show lower CO efficiency and lower TOF values at electrode potentials of region $3^{3,23}$.

\section{Discussion}

In this work, we found a family of solid, single site, $\mathrm{N}$-coordinated transition metal-functionalized nanoporous carbons that show very high electrocatalytic reactivity and selectivity with respect to the direct $\mathrm{CO}_{2}$ reduction to $\mathrm{CO}\left(\mathrm{CO}_{2} \mathrm{RR}\right)$. A technical challenge in these $\mathrm{M}-\mathrm{N}-\mathrm{C}$ catalyst is to achieve a high density of active $\mathrm{M}-\mathrm{N}_{x}$ sites, while minimizing effects of other nitrogen moieties and inorganic metal impurities, which, for this class of materials cannot be completely excluded. However, based on our experimental observation, we could confirm that the $\mathrm{M}-\mathrm{N}_{x}$ site play the dominant role during the $\mathrm{CO}_{2} \mathrm{RR}$ process into $\mathrm{CO}$. For instance, the $\mathrm{Co}-\mathrm{N}_{x}$ sites were efficient hydrogen producers whereas the $\mathrm{Fe}-$ and $\mathrm{Ni}-\mathrm{N}_{x}$ single site catalysts showed a unique reactivity and faradaic efficiency for reducing $\mathrm{CO}_{2}$ into $\mathrm{CO}$, meeting and exceeding the mass-based activity of state-of-art $\mathrm{Au}$ catalysts at a fraction of their cost.

To understand the trends in reactivity and selectivity of the single site catalysts we have correlated our experimental results with DFT simulations of the energetics of the competing reaction pathways involved. Our results demonstrate that the binding energies can be used as descriptors to predict the $\mathrm{CO}_{2} \mathrm{RR}$ activity and selectivity of this class of catalysts. This is why we find a good agreement between the DFT predictions and the catalytic experiments offering a detailed mechanistic understanding of the role of the metal centers in the considered catalytic processes.

Consistent with experiments, Co- $\mathrm{N}_{x}$ sites displayed alldownhill energetics for hydrogen, but severe energetic barriers to $\mathrm{CO}$ formation. By contrast, the low $\mathrm{H}^{*}$ and $\mathrm{CO}^{*}$ binding energy of the $\mathrm{Ni}-\mathrm{N}_{x}$ single site required larger overpotentials to jump start the reactions. At larger overpotentials, however, $\mathrm{Ni}-\mathrm{N}_{x}$ catalysts displayed all-downhill energetics toward $\mathrm{CO}$, while hydrogen evolution is hindered.
The high $\mathrm{CO}$ efficiency at medium and large overpotentials of the $\mathrm{Fe}-\mathrm{N}-\mathrm{C}$ and $\mathrm{Ni}-\mathrm{N}-\mathrm{C}$ materials combined with their earth-abundant constituents, compared with standard $\mathrm{Au}$ catalysts, makes them attractive catalysts for deployment in future industrial $\mathrm{CO}_{2}$-consuming $\mathrm{CO}$ cathodes for use as counter electrode process in the chlorine production industry. The choice of catalyst thereby becomes a tradeoff between voltage efficiency ( $\mathrm{Fe}$ produces most $\mathrm{CO}$ at lower potentials) and turnover frequency/current density ( $\mathrm{Ni}$ makes most $\mathrm{CO}$ at higher overpotentials). In particular for $\mathrm{Ni}-\mathrm{N}-\mathrm{C}$ catalysts, high $\mathrm{CO}$ efficiencies at current densities approaching industrial levels make them suitable candidates for $\mathrm{CO}_{2}$-consuming gas-diffusion cathode (CCC) designs to be deployed in next-generation chloralkaline electrolyzers. By eliminating the need for fossil fuel-based steam reforming toward purified $\mathrm{CO}$ feed streams in the Chlorine-mediated polymer industry, $\mathrm{CO}_{2}$ reuse in chlorine- $\mathrm{CO}$ co-electrolyzers would significantly contribute to a lowering of industrial $\mathrm{CO}_{2}$ emissions worldwide.

\section{Methods}

Synthesis. All chemicals were used as received. Typically, 4,4'-Dipyridyl hydrate (bipy, $1.114 \mathrm{~g}$, Sigma-Aldrich Co.) was dissolved in $100 \mathrm{~mL}$ ethanol solution. A certain amount of $\mathrm{CoCl}_{2} \cdot 6 \mathrm{H}_{2} \mathrm{O}(1.2 \mathrm{~g})$ was dissolved in $900 \mathrm{~mL}$ DI water solution. Then the bipy solution was mixed with a $\mathrm{CoCl}_{2} \cdot 6 \mathrm{H}_{2} \mathrm{O}$ solution and left standing for $24 \mathrm{~h}$ without stirring. Then, $50 \mathrm{~mL} \mathrm{CuCl}{ }_{2} \cdot 2 \mathrm{H}_{2} \mathrm{O}(0.1 \mathrm{M})$ solution was rapidly mixed with the bpy-Co $\mathrm{Co}^{2+}$ solution and aged for $4 \mathrm{~h}$. Subsequently, the resultant product was collected by centrifugation with the speed of 4200 r.p.m. for $12 \mathrm{~min}$. After drying, the polymer product was carbonized at $500{ }^{\circ} \mathrm{C}$ for $2 \mathrm{~h}$ at a heating rate of $60^{\circ} \mathrm{C} \mathrm{h}^{-1}$ in Ar atmosphere. Finally, hydrophilic N-doped porous carbons (N-C) with trace amounts of $\mathrm{Cu}$ were obtained after leaching in $4 \mathrm{M} \mathrm{HNO}_{3}$ for $24 \mathrm{~h}$.

Subsequently, additional transition metal species $(\mathrm{M}=\mathrm{Mn}, \mathrm{Fe}, \mathrm{Co}, \mathrm{Ni})$ were introduced in $\mathrm{N}-\mathrm{C}$ through incipient impregnation of $\mathrm{MCl}_{x}$ solutions. The nominal weight concentration of $\mathrm{M}$ respective to $\mathrm{N}-\mathrm{C}$ was set to $25 \mathrm{wt} \%$. The dried M-N-C composite was re-pyrolyzed at $900{ }^{\circ} \mathrm{C}$ for $2 \mathrm{~h}$ at a heating rate of $2.0^{\circ} \mathrm{C}$ $\mathrm{min}^{-1}$ in Ar atmosphere. The carbonized $\mathrm{M}-\mathrm{N}-\mathrm{C}$ was dispersed in aqueous sulfuric acid (ca. $2.0 \mathrm{~mol} \mathrm{~L}^{-1}$ ) and refluxed at $100^{\circ} \mathrm{C}$ for 1 day. The leached sample was collected and washed with DI water until $\mathrm{pH}$ value close to neutral. Finally, the leached sample was treated at $900{ }^{\circ} \mathrm{C}$ first in Ar for $2 \mathrm{~h}$, and then in $\mathrm{H}_{2}$ for another $1 \mathrm{~h}$, then again in Ar, let cool down and harvest the final $\mathrm{M}-\mathrm{N}-\mathrm{C}$ electrocatalysis $(\mathrm{M}=\mathrm{Mn}, \mathrm{Fe}, \mathrm{Co}, \mathrm{Ni})$. The $\mathrm{Cu}-\mathrm{N}-\mathrm{C}$ material was obtained directly after the reductive annealing procedure without any additional acid leaching.

Physico-chemical characterization. Scanning electron microscope (SEM) investigations were carried out with a Hitachi SU8020 instrument. A FEI Tecnai G2 F20 microscope that was equipped with HAADF-STEM and EDAX detectors was employed to acquire the HAADF-STEM images and EDX elemental maps. XPS measurements were carried out in an ultra-high vacuum (UHV) system equipped with a monochromatic $\mathrm{Al} \mathrm{K} \alpha \mathrm{X}$-ray source $(1486.6 \mathrm{eV}$; anode operating at $12.25 \mathrm{kV}$ and $300 \mathrm{~W}$ ) and a high-resolution Phoibos $150 \mathrm{MCD}$ analyzer (SPECS). X-ray photoemission spectra were measured in fixed analyzer transmission mode with a pass energy of $15 \mathrm{eV}$ and step size of 0.5 and $0.05 \mathrm{eV}$ for survey and high-resolution region scans correspondingly. The binding energy scale was adjusted assigning the signal of graphitic carbon to $285 \mathrm{eV}$. Raman spectra were measured on a Renishaw Ramascope RM 2000 Raman microscope $(\times 50$, na $=0.75)$ with a REM Laser from Laserquantum (wavelength: $532 \mathrm{~nm}$ ). The peak parameters were extracted by curve fitting on the Renishaw Wire 2.0 software, where a mixed Gaussian and Lorentzian function was used, and the maximum of the first curve is defined on $1170 \mathrm{~cm}^{-1}$. Nitrogen sorption isotherms were measured on a BELSORP adsorption analyzer at liquid nitrogen temperature. The specific surface area was calculated based on adsorption points in the relative pressure of $0.05<\mathrm{P} / \mathrm{P} 0<0.20$ according to Brunauer-Emmett-Teller (BET) theory. Pore size distributions (PSDs) were derived from the adsorption branches of the isotherms based on Non Localized Density Functional Theory (NLDFT, nitrogen on carbon slit adsorption branch kernel). Water physisorption measurements were carried out on a Quantachrome Hydrosorb 1000. $\mathrm{CO}_{2}$ adsorption isotherms were measured on a Autosorb iQ MP micropore analyzers at $273 \mathrm{~K}$. Before gas or vapor physisorption measurements, the samples were degassed at $150^{\circ} \mathrm{C}$ for at least $12 \mathrm{~h}$.

Electrochemical measurements. The electrochemical measurements were controlled with EC-Lab SP-200 Potentiostat. Resistance between reference electrode and working electrode was measured with Potential Electrochemical Impedance Spectroscopy (PEIS). $50 \%$ of the resistance was corrected by the software and the rest was manually corrected. $\mathrm{CO}_{2}$ electrolysis was carried out in a custom-made two-compartment cell, in which the working electrode was separated from the 
counter electrode by Nafion membrane to hinder the re-oxidation of the products on the counter electrode. The glassware was cleaned in nochromix mixed sulfuric acid bath and afterwards in concentrated $\mathrm{HNO}_{3}$ for $1 \mathrm{~h}$, respectively, rinsed and sonicated with $80^{\circ} \mathrm{C}$ ultrapure water several times, and dried at $60^{\circ} \mathrm{C}$ in an oven. Each compartment of the cell was filled with $40 \mathrm{~mL} \mathrm{CO}_{2}$ (Air liquid 4.5, flow from button, rate: $30 \mathrm{~mL} \mathrm{~min}^{-1}$ ) purged electrolyte. A Pt mesh 100 (Sigma-Aldrich 99.9\%) was used as counter electrode (CE) and a leak-free $\mathrm{Ag} / \mathrm{AgCl}$ electrode (Hugo Sachs Elektronik Harvard apparatus $\mathrm{GmbH}$ ) was used as the reference electrode. The $\mathrm{CO}_{2}$ free measurements were carried out in $\mathrm{N}_{2}$-saturated $0.1 \mathrm{M}$ $\mathrm{KH}_{2} \mathrm{PO}_{4} / \mathrm{K}_{2} \mathrm{HPO}_{4}$ (Sigma-Aldrich, $\mathrm{pH}$ of 6.9), while the $\mathrm{CO}_{2}$ electrolysis in presence of $\mathrm{CO}_{2}$ was done in $0.1 \mathrm{M} \mathrm{KHCO}_{3}$ (Sigma-Aldrich, $\mathrm{pH}$ of 6.8).

Catalytic product analysis. After $15 \mathrm{~min}$ and $60 \mathrm{~min}$ of bulk $\mathrm{CO}_{2}$ electrolysis at constant working potential, a sample of the gas was analyzed by gas chromatography (Shimadzu GC 2014, Haye.Sep Q (Col-No. CS 1015-03) + Haye.Sep R (ColNo. CS 1015-07), TCD and FID detector) to quantify the instant Production Rate and Faradaic Selectivity of the gaseous products. In addition, $2 \mathrm{ml}$ of the electrolyte after reaction was analyzed by high performance liquid chromatograph (HPLC Agilent 1200, Zimmer Chromatography ${ }^{\circledR}$ Column, RID detector) to measure formic acid concentration and analyzed by liquid injection gas chromatography (Shimadzu GC 2010 plus, Fused-Silica-Capillary Column, REF 72306030, FID Detector) for alcohol products.

DFT calculations and predictions. The porphyrin-like structure was created in $\mathrm{ASE}^{57}$ by a $3 \times 5$ unit cell of graphene and functionalized by removing carbon atoms to create the metal-nitrogen site. Further, the outmost carbon atoms were fixed in position and periodic boundaries were applied. This setup is hereby almost similar to Tripcovic ${ }^{47}$ and revealed similar results when applying the same references. For the electronic calculations the projector augmented wave method together with spin polarization and the revised Perdew-Burke-Ernzerhof (RPBE $)^{58}$ functional was performed with the GPAW software ${ }^{59,60}$. We applied a 0.18 grid spacing together with a $(2 \times 2 \times 1) \mathrm{k}$-point sampling and all the structure were relaxed to a force below $0.1 \mathrm{eV} / \AA$. To calculate the free energy diagrams, the hydrogen electrode was employed ${ }^{6}$. For this we use zero point, entropy and heat capacity values from reference ${ }^{62}$. Finally, the $\mathrm{CO}_{2}$ calculated RPBE energy was corrected by $0.45 \mathrm{eV}$ together with a $-\mathrm{COH}$ water correction of $0.25 \mathrm{eV}$ and $\mathrm{a}{ }^{*} \mathrm{CO}$ water correction of $0.1 \mathrm{eV}^{63}$

Data availability. DFT structures and binding energies will be available online in our group webpage (Rossmeisl) upon publication. Experimental data is available from the authors upon reasonable request.

Received: 14 February 2017 Accepted: 7 August 2017

Published online: 16 October 2017

\section{References}

1. Huei-Ru, M. J., Sichao, Ma. \& Paul, J. A. K. Electrochemical conversion of $\mathrm{CO}_{2}$ to useful chemicals: current status, remaining challenges, and future opportunities. Curr. Opin. Chem. Eng. 2, 191-199 (2013).

2. Jacob, S., Jia, H., Muckerman, J. T. \& Fujita, E. Thermodynamics and kinetics of $\mathrm{CO}_{2}, \mathrm{CO}$, and $\mathrm{H}+$ binding to the metal centre of $\mathrm{CO}_{2}$ reductioncatalysts. Chem. Soc. Rev. 41, 2036-2051 (2012).

3. Hori, Y., Murata, A. \& Takahashi, R. Formation of hydrocarbons in the electrochemical reduction of carbon dioxide at a copper electrode in aqueous solution. J. Chem. Soc. Faraday Trans. 85, 2309-2326 (1989).

4. Akira, M. \& Hori, Y. Product selectivity affected by cationic species in electrochemical reduction of $\mathrm{CO}_{2}$ and $\mathrm{CO}$ at a $\mathrm{Cu}$ electrode. Bull. Chem. Soc. Jpn 64, 123-127 (1991).

5. Varela, A. S., Kroschel, M., Reier, T., Strasser, P. Controlling the selectivity of $\mathrm{CO}_{2}$ electroreduction on copper: the effect of the electrolyte concentration and the importance of the local pH. Catal. Today 260, 8-13 (2015).

6. Varela, A. S., Ju, W., Reier, T. \& Strasser, P. Tuning the catalytic activity and selectivity of $\mathrm{Cu}$ for $\mathrm{CO}_{2}$ electroreduction in the presence of halides. ACS Catal. 6, 2136-2144 (2016)

7. Kuhl, K., Cave, E., Abram, D. N. \& Jaramillo, T. F. New insights into the electrochemical reduction of carbon dioxide on metallic copper surfaces. Energy Environ. Sci. 5, 7050-7059 (2012)

8. Tang, W. et al. The importance of surface morphology in controlling the selectivity of polycrystalline copper for $\mathrm{CO}_{2}$ electroreduction. Phys. Chem. Chem. Phys. 14, 76-81 (2012).

9. $\mathrm{Li}, \mathrm{C} . \mathrm{W}$. \& Kanan, M. W. $\mathrm{CO}_{2}$ reduction at low overpotential on $\mathrm{Cu}$ electrodes resulting from the reduction of thick $\mathrm{Cu}_{2} \mathrm{O}$ Films. J. Am. Chem. Soc. 134, 7231-7234 (2012)
10. Mistry, H. et al. Highly selective plasma-activated copper catalysts for carbon dioxide reduction to ethylene. Nat. Commun 7, 12123 (2016).

11. Schouten, K. J. P., Q., Z., Gallent, E. P. \& Koper, M. T. M. Two pathways for the formation of ethylene in $\mathrm{CO}$ reduction on single-crystal copper electrodes. J. Am. Chem. Soc. 134, 9864-9867 (2012).

12. Calle-Vallejo, F. \& Koper, M. T. M. Theoretical considerations on the electroreduction of $\mathrm{CO}$ to $\mathrm{C} 2$ species on $\mathrm{Cu}(100)$ electrodes. Angew. Chem. Int. Ed. 125, 7423-7426 (2013).

13. Hori, Y., Takahashi, I., Koga, O. \& Hoshi, N. Electrochemical reduction of carbon dioxide at various series of copper single crystal electrodes. J. Mol. Catal. A Chem. 199, 39-47 (2003).

14. Roberts, F. S., Kuhl, K. P. \& Nilsson, A. A. High selectivity for ethylene from carbon dioxide reduction over copper nanocube electrocatalysts. Angew. Chem. Int. Ed. 127, 5268-5271 (2015).

15. Reske, R., Mistry, H., Behafarid, F., Roldan Cuenya, B. \& Strasser, P. Particle size effects in the catalytic electroreduction of $\mathrm{CO}_{2}$ on $\mathrm{Cu}$ nanoparticles. J. Am Chem. Soc. 136, 6978-6986 (2014).

16. Mistry, $\mathrm{H}$. et al. Tuning catalytic selectivity at the mesoscale via interparticle interactions. ACS Catal. 6, 1075-1080 (2016).

17. Mistry, H., Varela, A. S., Kühl, S., Strasser, P. \& Cuenya, B. R. Nanostructured electrocatalysts with tunable activity and selectivity. Nat. Rev. Mater. 1, 16009 (2016).

18. Zhang, S. et al. Polymer-supported CuPd nanoalloy as a synergistic catalyst for electrocatalytic reduction of carbon dioxide to methane. Proc. Natl Acad. Sci. 112, 15809-15814 (2015).

19. Rasul, S. et al. A highly selective copper-indium bimetallic electrocatalyst for the electrochemical reduction of aqueous $\mathrm{CO}_{2}$ to CO. Angew. Chem. Int. Ed. 127, 2174-2178 (2015).

20. Sarfraz, S., Garcia-Esparza, A. T., Jedidi, A., Cavallo, L. \& Takanabe, K. Cu-Sn bimetallic catalyst for selective aqueous electroreduction of $\mathrm{CO}_{2}$ to $\mathrm{CO}$. ACS Catal. 6, 2842-2851 (2016).

21. Lu, Q., Rosen, J. \& Jiao, F. Nanostructured metallic electrocatalysts for carbon dioxide reduction. ChemCatChem 7, 1-11 (2015).

22. Mistry, H. et. al. Enhanced carbon dioxide electroreduction to carbon monoxide over defect-rich plasma-activated silver catalysts. Angew. Chem. Int Ed. 56, 11394-11398 (2017).

23. Hori, Y. in Modern Aspects of Electrochemistry Vol. 42 (ed. Vayenas, C.) Ch. 3 , 89-189 (Springer, 2008).

24. Chen, Y., Li, C. W. \& Kanan, M. W. Aqueous $\mathrm{CO}_{2}$ reduction at very low overpotential on oxide-derived Au nanoparticles. J. Am. Chem. Soc 134, 19969-19972 (2012).

25. Zhu, W. et al. Monodisperse Au nanoparticles for selective electrocatalytic reduction of $\mathrm{CO}_{2}$ to CO. J. Am. Chem. Soc 135, 16833-16836 (2013).

26. Zhu, W. et al. Active and selective conversion of $\mathrm{CO}_{2}$ to $\mathrm{CO}$ on ultrathin $\mathrm{Au}$ nanowires. J. Am. Chem. Soc 136, 16132-16135 (2014).

27. Mistry, $\mathrm{H}$. et al. Exceptional size-dependent activity enhancement in the electroreduction of $\mathrm{CO}_{2}$ over $\mathrm{Au}$ nanoparticles. J. Am. Chem. Soc. 136, 16473-16476 (2014).

28. Jovanov, Z. P. et al. Opportunities and challenges in the electrocatalysis of $\mathrm{CO}_{2}$ and $\mathrm{CO}$ reduction using bifunctional surfaces: a theoretical and experimental study of Au-Cd alloys. J. Catal. 343, 215-231 (2016).

29. Hammouche, M., Lexa, D. \& Savéant, J. M. Catalysis of the electrochemical reduction of carbon dioxide by iron("0") porphyrins. J. Electroanal. Chem. Interfacial Electrochem. 249, 347-351 (1988).

30. Bhugun, I., Lexa, D. \& Savéant, J.-M. Catalysis of the electrochemical reduction of carbon dioxide by iron (0) porphyrins: synergystic effect of weak Brönsted acids. J. Am. Chem. Soc. 118, 1769-1776 (1996).

31. Costentin, C., Drouet, S., Robert, M. \& Savéant, J.-M. A local proton source enhances $\mathrm{CO}_{2}$ electroreduction to $\mathrm{CO}$ by a molecular Fe catalyst. Science 338, 90-94 (2012).

32. Kornienko, N. et al. Metal-organic frameworks for electrocatalytic reduction of carbon dioxide. J. Am. Chem. Soc. 137, 14129-14135 (2015).

33. Varela, A. S. et al. Metal-doped nitrogenated carbon as an efficient catalyst for direct $\mathrm{CO}_{2}$ electroreduction to $\mathrm{CO}$ and hydrocarbons. Angew. Chem. Int. Ed. 54, 10758-10762 (2015).

34. J. Shen, M. J. Kolb, A. J. Göttle, M. T. M. Koper DFT study on the mechanism of the electrochemical reduction of $\mathrm{CO}_{2}$ catalyzed by cobalt porphyrins. J. Phys. Chem. C 120, 15714-15721 (2016).

35. Shen, J. et al. Electrocatalytic reduction of carbon dioxide to carbon monoxide and methane at an immobilized cobalt protoporphyrin. Nat. Commun. 6, 8177 (2015).

36. Wu, G., More, K. L., Johnston, C. M. \& Zelenay, P. High-performance electrocatalysts for oxygen reduction derived from polyaniline, iron, and cobalt. Science 332, 443-447 (2010).

37. Sahraie, N. R., Paraknowitsch, J. P., Göbel, C., Thomas, A. \& Strasser, P. Noblemetal-free electrocatalysts with enhanced ORR performance by task-specific functionalization of carbon using ionic liquid precursor systems. J. Am. Chem. Soc. 136, 14486-14497 (2014). 
38. Sahraie, N. R. et al. Quantifying the density and utilization of active sites in non-precious metal oxygen electroreduction catalysts. Nat. Commun. 6, 8618 (2015).

39. Masa, J., Xia, W., Muhler, M. \& Schuhmann, W. On the role of metals in nitrogen-doped carbon electrocatalysts for oxygen reduction. Angew. Chem. Int. Ed. 54, 2-21 (2015).

40. Kramm, U. I. et al. Structure of the catalytic sites in Fe/N/C-catalysts for $\mathrm{O}_{2}$-reduction in PEM fuel cells. Phys. Chem. Chem. Phys. 14, 11673-11688 (2012).

41. Kumar, B. et al. Renewable and metal-free carbon nanofibre catalysts for carbon dioxide reduction. Nat. Commun. 4, 2819 (2013).

42. Zhang, S. et al. Polyethylenimine-enhanced electrocatalytic reduction of $\mathrm{CO}_{2}$ to formate at nitrogen-doped carbon nanomaterials. J. Am. Chem. Soc. 136 7845-7848 (2014).

43. Sharma, P. P. et al. Nitrogen-doped carbon nanotube arrays for high-efficiency electrochemical reduction of $\mathrm{CO}_{2}$ : on the understanding of defects, defect density, and selectivity. Angew. Chem. Int. Ed. 54, 13701-13705 (2015).

44. Jingjie, $\mathrm{Wu}$ et al. Incorporation of nitrogen defects for efficient reduction of $\mathrm{CO}_{2}$ via two-electron pathway on three-dimensional graphene foam. Nano Letter 16, 466-470 (2016).

45. $\mathrm{Xu}, \mathrm{J}$. et al. Revealing the origin of activity in nitrogen-doped nanocarbons towards electrocatalytic reduction of carbon dioxide. Chemsuschem $\mathbf{9}$, 1085-1089 (2016).

46. Jingjie, Wu et al. A metal-free electrocatalyst for carbon dioxide reduction to multi-carbon hydrocarbons and oxygenates. Nat. Commun. 7, 13869 (2016).

47. Tripkovic, V. et al. Electrochemical $\mathrm{CO}_{2}$ and $\mathrm{CO}$ reduction on metalfunctionalized porphyrin-like graphene. J. Phys. Chem. C 117, 9187-9195 (2013).

48. Bagger, A., Ju, W., Varela, A. S., Strasser, P. \& Rossmeisl, J. Single site porphyrine-like structures advantages over metals for selective electrochemical $\mathrm{CO}_{2}$ reduction. Catal. Today 288, 74-78 (2017).

49. Hao, G.-P. et al. Structurally designed synthesis of mechanically stable poly (benzoxazine-co-resol)-based porous carbon monoliths and their application as high-performance $\mathrm{CO}_{2}$ capture sorbents. J. Am. Chem. Soc. 133, 11378-11388 (2011).

50. Kabir, S., Artyushkova, K., Kiefer, B. \& Atanassov, P. Computational and experimental evidence for a new TM-N 3/C moiety family in non-PGM electrocatalysts. Phys. Chem. Chem. Phys. 17, 17785-17789 (2015).

51. Artyushkova, K. et al. Density functional theory calculations of XPS binding energy shift for nitrogen-containing graphene-like structures. Chem. Commun. 49, 2539-2541 (2013).

52. C. D. Wagner et al. NIST Standard Reference Database 20. (2003).

53. Li, Y., Su, H., Chan, S. H. \& Sun, Q. $\mathrm{CO}_{2}$ electroreduction performance of transition metal dimers supported on graphene: a theoretical study. ACS Catal. 5, 6658-6664 (2015).

54. Back, S., Lim, J., Kim, N.-Y., Kim, Y.-H. \& Jung, Y. Single-atom catalysts for $\mathrm{CO}_{2}$ electroreduction with significant activity and selectivity improvements. Chem. Sci. 8, 1090-1096 (2017).

55. Shen, H., Li, Y. \& Sun, Q. $\mathrm{CO}_{2}$ electroreduction performance of phthalocyanine sheet with mn dimer: a theoretical study. J. Phys. Chem. C 121, 3963-3969 (2017).

56. M. Busch et al. Beyond the top of the volcano? - A unified approach to electrocatalytic oxygen reduction and oxygen evolution. Nano Energy 29, 2211-2855 (2016).

57. Bahn, S. R. \& Jacobsen, K. W. An object-oriented scripting interface to a legacy electronic structure code. Comput. Sci. Eng. 4, 56-66 (2002).

58. Hammer, B. H., Hansen, L. B. \& Nørskov, J. K. Improved adsorption energetics within density-functional theory using revised perdew-burke-ernzerhof functionals. Phys. Rev. B 59, 7413-7421 (1999).

59. Mortensen, J. J., Hansen, L. B. \& Jacobsen, K. W. Real-space grid implementation of the projector augmented wave method. Phys. Rev. B 71, 035019 (2005).
60. Enkovaara, J. R. et al. Electronic structure calculations with GPAW: a real-space implementation of the projector augmented-wave method. J. Phys.: Condens. Matter 22, 253202 (2010).

61. Nørskov, J. K. et al. Origin of the overpotential for oxygen reduction at a fuelcell cathode. J. Phys. Chem. B 108, 17886-17892 (2004).

62. Chan, K., Tsai, C., Hansen, H. A. \& Nørskov, J. K. Molybdenum sulfides and selenides as possible electrocatalysts for $\mathrm{CO}_{2}$ reduction. ChemCatChem $\mathbf{6}$, 1899-1905 (2014).

63. Peterson, A. A., Abild-Pedersen, F., Studt, F., Rossmeisl, J. \& Nørskov, J. K. How copper catalyzes the electroreduction of carbon dioxide into hydrocarbon fuels. Energy Environ. Sci. 3, 1311-1315 (2010).

\section{Acknowledgements}

This work received funding by the European Community under the flagship "Climate $\mathrm{KIC} / \mathrm{EnCO} 2 \mathrm{re}$ " program as part of the Horizon2020 EU funding instrument. A.S.V., B.R.C., I.S., and P.S. are grateful for partial support by the German Federal Ministry of Education and Research (Bundesministerium für Bildung und Forschung, BMBF) under grant \#03SF0523A,C- “CO2EKAT”. Financial assistance from the Cluster of Excellence RESOLV at RUB (EXC 1069) funded by the Deutsche Forschungsgemeinschaft is also greatly appreciated. A.B. and J.R. acknowledge the Carlsberg Foundation (grant CF15-0165). We thank Dr. B. Zhang for STEM measurements, and Prof. Eychmüller for Raman analysis. G.-P.H. thanks Alexander von Humboldt Foundation for supporting the stay and research. W.J. acknowledges the financial support of China Scholarship Council (CSC)

\section{Author contributions}

P.S., W.J., and A.S.V. conceived and designed the experiments. J.R. and A.B. performed the DFT calculation. S.K., B.R.C., G.-P.H., I.S., and B.V. carried out the chemical synthesis, microscopic and spectroscopic characterization of the carbon-based materials and subsequent in depth data analysis. W.J. and A.S.V. carried out the electrocatalytic tests and analyzed the results. G.-P.H., P.S. and W.J. aggregated the figures and co-wrote the manuscript. All authors discussed the results, drew conclusions, and commented on the manuscript.

\section{Additional information}

Supplementary Information accompanies this paper at doi:10.1038/s41467-017-01035-Z.

Competing interests: The authors declare no competing financial interests.

Reprints and permission information is available online at http://npg.nature.com/ reprintsandpermissions/

Publisher's note: Springer Nature remains neutral with regard to jurisdictional claims in published maps and institutional affiliations.

Open Access This article is licensed under a Creative Commons Attribution 4.0 International License, which permits use, sharing, adaptation, distribution and reproduction in any medium or format, as long as you give appropriate credit to the original author(s) and the source, provide a link to the Creative Commons license, and indicate if changes were made. The images or other third party material in this article are included in the article's Creative Commons license, unless indicated otherwise in a credit line to the material. If material is not included in the article's Creative Commons license and your intended use is not permitted by statutory regulation or exceeds the permitted use, you will need to obtain permission directly from the copyright holder. To view a copy of this license, visit http://creativecommons.org/ licenses/by/4.0/

(C) The Author(s) 2017 